\title{
Hemorrhagic 'spider-in-web': atypical appearance of a peritoneal inclusion cyst
}

\author{
Jonathan R. Dillman • Michael A. DiPietro
}

Received: 4 March 2009 / Accepted: 1 April 2009 / Published online: 20 May 2009

(C) Springer-Verlag 2009

A 16-year-old girl with short-gut syndrome and multiple surgical procedures for adhesion-related small-bowel obstructions presented with pelvic pain. Right adnexal sonography revealed a complicated cystic mass that contained a structure thought to be the right ovary (Fig. 1). Power Doppler US image (Fig. 2) showed blood flow surrounding a hemorrhagic ovarian cyst (asterisk). A small amount of normal ovarian tissue was seen (arrows). Laparoscopy and histopathology confirmed an entrapped right ovary within a peritoneal inclusion cyst (PIC). The ovary was preserved and contained a large hemorrhagic functional cyst.

PICs form when ovulatory fluid accumulates between peritoneal adhesions related to prior surgery, infection, or inflam-



Fig. 1 Gray-scale US image

J. R. Dillman $(\bowtie) \cdot$ M. A. DiPietro

Department of Radiology, C.S. Mott Children's Hospital/F3503,

University of Michigan Health System,

1500 E. Medical Center Dr.,

Ann Arbor, MI 48109-5252, USA

e-mail: jonadill@med.umich.edu

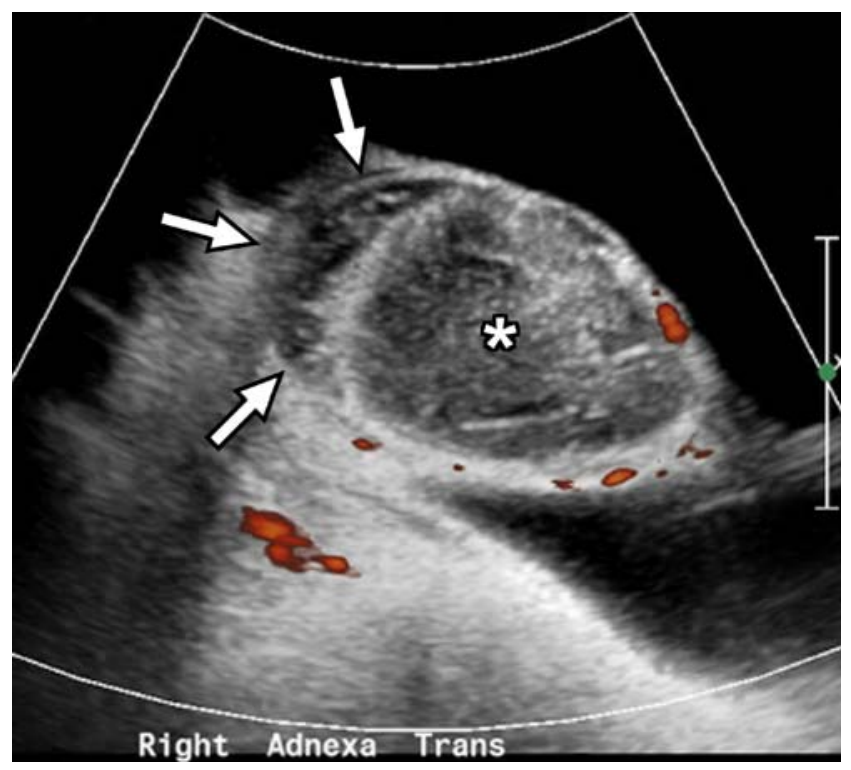

Fig. 2 Power Doppler US image

mation $[1,2]$. An ovary entrapped within a PIC has been described as having a "spider-in-web" appearance and must not be confused for hydrosalpinx or ovarian malignancy $[1,2]$. The presence of a hemorrhagic ovarian cyst (hemorrhagic "spider"), thick septations, and complicated fluid, all findings in our case, may make the differentiation of PIC from ovarian cystic neoplasm difficult. Recognition of this entity prevents needless oophorectomy and guides appropriate management, such as percutaneous aspiration or adhesiotomy $[1,2]$.

\section{References}

1. Kim JS, Lee HJ, Woo SK et al (1997) Peritoneal inclusion cysts and their relationship to the ovaries: evaluation with sonography. Radiology 204:481-484

2. Jain KA (2000) Imaging of peritoneal inclusion cysts. AJR 174:1559-1563 